\title{
AKUMULASI LOGAM BERAT PADA DAUN Echinodorus palaefolius PADA VARIASI MEDIA PENYARING SELAMA REMEDIASI AIR LINDI
}

\author{
Ermina Sari ${ }^{1)}$, Martala Sari ${ }^{2)}$, Raudhah Awal ${ }^{3)}$, Arlian Firda ${ }^{4)}$ \\ ${ }^{1), 2,3), 4)}$ Program Studi Pendidikan Biologi, Universitas Lancang Kuning \\ Email ${ }^{1)}$ :erminasari@unilak.ac.id \\ Email ${ }^{2)}$ :martalasari@unilak.ac.id \\ Email $^{3)}$ :raudhahawal@unilak.ac.id \\ Email ${ }^{4)}$ :arlian_arai@unilak.ac.id
}

\begin{abstract}
ABSTRAK : Persoalan sampah di Pekanbaru merupakan salah satu hal yang sangat diresahkan masyarakat sekitar. Karena, jumlah peningkatan sampah yang melebihi kapasitas dapat mencemari lingkungan dan akan menjadi substansi cairan yang dihasilkan dalam proses pembusukan sampah yang baunya sangat menyengat, yang disebut dengan air lindi. Penelitian ini bertujuan untuk mengetahui berapa kadar logam berat $\mathrm{Fe}$ dan $\mathrm{Cr}$ yang terakumulasi di daun melati air (Echinodorus palaefolius) selama remediasi air lindi (leachate). Penelitian ini merupakan penelitian eksperimen dengan Rancangan Acak Lengkap (RAL) yang terdiri dari 4 perlakuan dan 5 kali pengulangan setiap perlakuan. Hasil penelitian menunjukkan bahwa kadar logam berat $\mathrm{Fe}$ dan $\mathrm{Cr}$ yang terakumulasi pada daun melati air (Echinodorus palaefolius) paling banyak terdapat pada perlakuan 1 (P1) hari ke 30 dengan menggunakan media penyaring Podzolik Merah Kuning (PMK) dengan tumbuhan melati air (Echinodorus palaefolius), nilai efektivitas akumulasi logam berat Fe pada daun melati air (Echinodorus palaefolius) sebesar 32,843\% $\mathrm{mg} / \mathrm{L}$ sedangkan nilai efektivitas akumulasi logam berat $\mathrm{Cr}$ pada daun melati air (Echinodorus palaefolius) sebesar 10,242\% mg/L. Dari hasil penelitian dapat disimpulkan bahwa media penyaring PMK dengan melati air (Echinodorus palaefolius) pada perlakuan 1 (P1) sangat berpengaruh terhadap akumulasi logam berat $\mathrm{Fe}$ dan $\mathrm{Cr}$ pada daun melati air (Echinodorus palaefolius) selama remediasi air lindi.
\end{abstract}

Kata kunci: media penyaring, logam berat, Echinodorus palaefolius, air lindi, fitoremediasi

ABSTRACT: The issue of waste in Pekanbaru is one of the things that the surrounding community is very worried about. Because, the amount of increase in waste that exceeds capacity can pollute the environment and will be a liquid substance produced in the process of decaying trash that smells very strong, which is called leachate. This study aims to determine the levels of heavy metals $\mathrm{Fe}$ and $\mathrm{Cr}$ which accumulate in the leaves of Echinodorus palaefolius during the remediation of leachate water. This research is an experimental research with Completely Randomized Design (CRD) which consists of 4 treatments and 5 repetitions of each treatment. The results showed that the highest levels of heavy metals $\mathrm{Fe}$ and $\mathrm{Cr}$ accumulated in the leaves of Echinodorus palaefolius were mostly found in treatment 1 (P1) day 30 using the Red Yellow Podzolic filter media $(P M K)$ with Echinodorus palaefolius, the effectiveness of the accumulation of Fe heavy metals on Echinodorus palaefolius leaves is $32.843 \% \mathrm{mg} / \mathrm{L}$ while the 
effectiveness of heavy metal accumulation $\mathrm{Cr}$ in Echinodorus palaefolius leaves is $10.242 \% \mathrm{mg} / \mathrm{L}$. From the results of the study it can be concluded that the PMK filter media with Echinodorus palaefolius at treatment 1 (P1) greatly influences the accumulation of heavy metals $\mathrm{Fe}$ and $\mathrm{Cr}$ in Echinodorus palaefolius during leachate remediation.

Keywords: filter media, heavy metals, Echinodorus palaefolius, leachate, phytoremediation

\section{PENDAHULUAN}

Sampah di Tempat Pembuangan Akhir (TPA) masih mengalami proses penguraian secara alamiah dengan jangka waktu panjang. Beberapa jenis sampah dapat terurai secara cepat, sedangkan yang lainnya lebih lambat bahkan beberapa jenis sampah tidak berubah sampai puluhan tahun misalnya plastik. Hal ini memberikan gambaran bahwa setelah TPA selesai digunakan, masih ada proses yang berlangsung. Sehingga menghasilkan beberapa zat yang dapat mengganggu lingkungan (Sugiarto, 2013).

Persoalan sampah juga dapat mengancam kota Pekanbaru sebagai salah satu kota besar di Sumatera yang jumlah penduduknya terus meningkat. Sehingga kebutuhan penduduknya juga ikut meningkat. Berkaitan dengan itu, pemerintah kota Pekanbaru telah melakukan berbagai upaya penanggulangan sampah mulai dari kegiatan penyuluhan dan penyadaran masyarakat tentang kebersihan, penjemputan sampai dari rumahrumah penduduk untuk diangkut ke Tempat Pembuangan Akhir (TPA) sampah (Sari \& Sari, 2014).

Saat ini tempat pembuangan

akhir (TPA) Muara Fajar menerapkan sistem open dumping dalam pengolahan sampah dikarenakan jumlah peningkatan sampah yang melebihi kapasitas. Open dumping yaitu berupa area terbuka cukup luas yang digali atau bekas jurang. Area tersebut kemudian digunakan sebagai tempat pembuangan sampah dari segala penjuru kota (Sundari, 2015).

Agar sampah tersebut tidak mencemari lingkungan, keberadaan tempat pembuangan akhir (TPA) memiliki fungsi yang sangat penting, yaitu sebagai pengolahan akhir setelah disortir oleh pemulung. Jumlah sampah di TPA yang sangat besar akan menyebabkan proses dekomposisi alamiah berlangsung secara besar-besaran pula. Proses dekomposisi tersebut akan mengubah sampah menjadi pupuk organik dan menimbulkan hasil samping yaitu air lindi (Anam, 2011).

Air lindi (leachate) adalah substansi cairan yang dihasilkan dalam proses pembusukan sampah dan baunya sangat menyengat. Air lindi mengandung zat berbahaya apalagi jika berasal dari sampah yang tercampur dengan sampah B3 (Bahan berbahaya dan beracun). Jika tidak diolah secara khusus, air lindi dapat mencemari sumur/air tanah, air sungai, hingga air laut dan menyebabkan kematian biota (makhluk hidup) laut (Sari, 2015).

\section{METODE PENELITIAN}


Penelitian ini adalah eksperimen murni (True Exsperiment), dengan desain Rancangan Acak Lengkap (RAL) yang terdiri dari 4 perlakuan dan 5 kali pengulangan. Alat yang digunakan dalam penelitian ini adalah bak penampung, termometer, pH meter, kulkas, botol bekas, gelas kimia, dan aluminium foil. Bahan yang digunakan dalam penelitian ini adalah tanah jenis PMK, zeolit, ferrolit, air lindi, dan tanaman Melati
Air (Echinodorus palaefolius). Parameter yang diamati dalam penelitian adalah Kandungan Logam Berat Pada Daun Genjer diukur menggunakan AAS, Suhu diukur menggunakan thermometer, $\mathrm{pH}$ diukur menggunakan $\mathrm{pH}$ meter dan bau air lindi.

\section{HASIL DAN PEMBAHASAN}

Berdasarkan penelitian yang telah dilakukan maka diperoleh data sebagai berikut:

a. Suhu Air Lindi

Hasil pengamatan media penyaring terhadap suhu air lindi dalam setiap perlakuan selama 30 hari yang menggunakan Rancangan Acak Lengkap (RAL), maka didapat rekapitulasi data seperti tabel berikut.

Tabel 1: Rekapitulasi Suhu Air Lindi

\begin{tabular}{|c|c|c|c|c|c|}
\hline \multirow{2}{*}{ No } & \multirow{2}{*}{ Perlakuan } & \multicolumn{4}{|c|}{$\overline{\mathrm{X}}$ Suhu $\left({ }^{\circ} \mathrm{C}\right)$} \\
\cline { 3 - 6 } & & Hari 0 & Hari 10 & Hari 20 & Hari 30 \\
\hline 1 & P0 & 26 & 27 & 27 & 26 \\
\hline 2 & P1 & 26 & 26 & 27 & 27 \\
\hline 3 & P2 & 26 & 26 & 26 & 27 \\
\hline 4 & P3 & 25 & 26 & 26 & 26 \\
\hline
\end{tabular}

Keterangan: P0 : Kontrol (air lindi 10 liter tanpa perlakuan)

P1 : PMK 100\% + 4 rumpun melati air + Air lindi 10 liter

P2: PMK 50\% + zeolit 50\% + 4 rumpun melati air + Air lindi 10 liter

P3 : PMK 50\% + ferrolit 50\% + 4 rumpun melati air + Air lindi 10 liter

Berdasarkan Tabel 1 dapat dilihat bahwa nilai suhu air lindi memiliki nilai yang berbeda. Pada perlakuan 0 suhu pada hari 10 s.d. hari 30 masih belum stabil. Namun, pada perlakuan 1, 2, dan 3 mengalami peningkatan suhu. Hal ini disebabkan perhitungan suhu dilakukan di laboratorium. Suhu di laboratorium berkisar antara $25^{\circ} \mathrm{C}$ $27^{\circ} \mathrm{C}$, sedangkan suhu di halaman belakang laboratorium FKIP Unilak tempat penelitian berkisar antara $27^{\circ} \mathrm{C}-30^{\circ} \mathrm{C}$. Suhu yang tinggi tersebut dapat membuat tanaman melati air layu, namun setelah 10 hari melati air mampu beradaptasi dengan suhu tersebut. 
b. Bau Air Lindi

Dari pengamatan media penyaring terhadap bau air lindi dalam setiap perlakuan selama 30 hari yang menggunakan Rancangan Acak Lengkap (RAL), maka didapat rekapitulasi data seperti tabel 2 di bawah ini.

Tabel 2 : Rekapitulasi Bau Air Lindi

\begin{tabular}{|c|c|c|c|c|}
\hline \multirow{2}{*}{ Perlakuan } & \multicolumn{4}{|c|}{ Bau Air Lindi } \\
\cline { 2 - 5 } & Hari 0 & Hari 10 & Hari 20 & Hari 30 \\
\hline P0 & Berbau & Berbau & Berbau & Berbau \\
\hline P1 & Berbau & Berbau & Berbau & Berbau \\
\hline P2 & Berbau & Berbau & Berbau & Tidak Berbau \\
\hline P3 & Berbau & Berbau & Berbau & Tidak Berbau \\
\hline
\end{tabular}

Keterangan: P0 : Kontrol (air lindi 10 liter tanpa perlakuan)

P1 : PMK 100\% + 4 rumpun melati air + Air lindi 10 liter

P2: PMK 50\% + zeolit 50\% + 4 rumpun melati air + Air lindi 10 liter

P3 : PMK 50\% + ferrolit 50\% + 4 rumpun melati air + Air lindi 10 liter

Berdasarkan tabel di atas dapat dilihat bahwa pada perlakuan 0 dan perlakuan 1 hari ke 0 hingga hari ke 30 semua perlakuan air lindi tetap berbau. Sedangkan pada perlakuan P2 dan P3 hari ke 0 hingga hari ke 20 air lindi tetap berbau namun mengalami perubahan menjadi tidak berbau pada hari terakhir penelitian yaitu hari ke 30.

c. Konsentrasi Logam Berat Fe pada Air Lindi

Berdasarkan pengamatan media penyaring terhadap logam berat Fe pada air lindi setiap perlakuan selama 30 hari menggunakan Rancangan Acak Lengkap (RAL), maka didapat rekapitulasi data seperti tabel berikut ini:

Tabel 3 : Rekapitulasi Konsentrasi Logam Berat Besi (Fe) pada Air Lindi

\begin{tabular}{|c|c|c|c|c|}
\hline \multirow{2}{*}{ Perlakuan } & \multicolumn{4}{|c|}{$\overline{\mathrm{X}}$ Konsentrasi Logam Berat Fe (mg/L) } \\
\cline { 2 - 5 } & Hari 0 & Hari 10 & Hari 20 & Hari 30 \\
\hline P0 & 3,327 & 3,328 & 3,325 & 3,340 \\
\hline P1 & 3,347 & 3,122 & 2,807 & 2,778 \\
\hline P2 & 3,329 & 3,238 & 3,204 & 3,121 \\
\hline P3 & 3,318 & 3,275 & 3,224 & 3,125 \\
\hline
\end{tabular}

Keterangan: P0: Kontrol (air lindi 10 liter tanpa perlakuan) 
P1 : PMK 100\% + 4 rumpun melati air + Air lindi 10 liter

P2: PMK 50\% + zeolit 50\% + 4 rumpun melati air + Air lindi 10 liter

P3 : PMK 50\% + ferrolit 50\% + 4 rumpun melati air + Air lindi 10 liter

Berdasarkan Tabel 3 dapat dilihat bahwa nilai konsentrasi $\mathrm{Fe}$ pada hari ke 0 s.d. hari ke 30 perlakuan ke 0 tidak jauh berbeda. Namun pada perlakuan 1, 2, dan 3 kadar Fe di air lindi setiap pengamatan per 10 hari selama 30 hari sama-sama mengalami penurunan kadar Fe. Hal ini menunjukkan adanya pengaruh dari perbedaan media penyaring dan tanaman melati air yang mempengaruhi kadar logam berat $\mathrm{Fe}$ tersebut.

d. Konsentrasi Logam Berat Cr pada Air Lindi

Berdasarkan pengamatan media penyaring terhadap logam berat $\mathrm{Cr}$ pada air lindi setiap perlakuan selama 30 hari menggunakan Rancangan Acak Lengkap (RAL), maka didapat rekapitulasi data seperti tabel berikut ini.

Tabel 4 : Rekapitulasi Konsentrasi Logam Berat Kromium (Cr) pada Air Lindi

\begin{tabular}{|c|c|c|c|c|}
\hline \multirow{2}{*}{ Perlakuan } & \multicolumn{4}{|c|}{$\overline{\mathrm{X}}$ Konsentrasi Logam Berat Cr (mg/L) } \\
\cline { 2 - 5 } & Hari 0 & Hari 10 & Hari 20 & Hari 30 \\
\hline P0 & 3,691 & 3,646 & 3,633 & 3,615 \\
\hline P1 & 3,680 & 3,378 & 3,226 & 3,218 \\
\hline P2 & 3,697 & 3,121 & 3,032 & 3,006 \\
\hline P3 & 3,707 & 3,254 & 3,212 & 3,154 \\
\hline
\end{tabular}

Keterangan: P0: Kontrol (air lindi 10 liter tanpa perlakuan)

P1 : PMK 100\% + 4 rumpun melati air + air lindi 10 liter

P2: PMK 50\% + zeolit 50\% + 4 rumpun melati air + air lindi 10 liter

P3 : PMK 50\% + ferrolit 50\% + 4 rumpun melati air + air lindi 10 liter

Berdasarkan Tabel 4 dapat dilihat bahwa nilai kadar $\mathrm{Cr}$ pada hari ke 0 s.d. hari ke 30 perlakuan 0 (P0), perlakuan $1(\mathrm{P} 1)$, perlakuan 2 (P2), dan perlakuan 3 (P3) mengalami penurunan kadar $\mathrm{Cr}$ pada air lindi. Hal ini menunjukkan bahwa perbedaan media penyaring dengan tanaman melati air sangat berpengaruh terhadap penurunan kadar logam berat $\mathrm{Cr}$ tersebut.

e. Akumulasi Logam Berat Fe pada Daun Melati Air

Berdasarkan pengamatan media penyaring terhadap logam berat $\mathrm{Fe}$ yang terakumulasi pada daun melati air setiap perlakuan selama 30 hari menggunakan Rancangan Acak Lengkap (RAL), 
maka didapat rekapitulasi data seperti tabel berikut ini:

Tabel 5 : Rekapitulasi Konsentrasi Logam Berat Besi (Fe) yang Terakumulasi pada Daun Melati Air

\begin{tabular}{|c|c|c|c|c|}
\hline \multirow{2}{*}{ Perlakuan } & \multicolumn{4}{|c|}{ X Konsentrasi Logam Fe pada Daun (mg/L) } \\
\cline { 2 - 5 } & Hari 0 & Hari 10 & Hari 20 & Hari 30 \\
\hline P1 & 2,255 & 2,389 & 2,534 & 2,796 \\
\hline P2 & 2,255 & 2,384 & 2,525 & 2,636 \\
\hline P3 & 2,255 & 2,384 & 2,438 & 2,586 \\
\hline
\end{tabular}

Keterangan: P1 : PMK 100\% + 4 rumpun melati air + air lindi 10 liter

P2: PMK 50\% + zeolit 50\% + 4 rumpun melati air + air lindi 10 liter

P3 : PMK $50 \%$ + ferrolit $50 \%+4$ rumpun melati air + air lindi 10 liter

Berdasarkan Tabel 5 dapat dilihat bahwa kadar $\mathrm{Fe}$ yang terakumulasi pada daun melati air hari ke 0 s.d. hari ke 30 perlakuan 1 $(\mathrm{P} 1)$, perlakuan $2(\mathrm{P} 2)$, dan perlakuan 3 (P3) mengalami peningkatan kadar Fe yang terakumulasi pada daun melati air. Hal ini menunjukkan bahwa perbedaan media penyaring dengan tanaman melati air sangat

Tabel 6 : Rekapitulasi pH Air Lindi

\begin{tabular}{|c|c|c|c|c|}
\hline \multirow{2}{*}{ Perlakuan } & \multicolumn{4}{|c|}{ pH Air Lindi } \\
\cline { 2 - 5 } & Hari 0 & Hari 10 & Hari 20 & Hari 30 \\
\hline P0 & 9,5 & 9,1 & 8,8 & 8,6 \\
\hline P1 & 9,4 & 8,3 & 8,4 & 8,2 \\
\hline P2 & 9,4 & 8,4 & 8,1 & 8,4 \\
\hline P3 & 9,5 & 9,2 & 8,6 & 8,4 \\
\hline
\end{tabular}

Keterangan: P0: Kontrol (air lindi 10 liter tanpa perlakuan)

P1 : PMK 100\% + 4 rumpun melati air + air lindi 10 liter

P2: PMK 50\% + zeolit 50\% + 4 rumpun melati air + air lindi 10 liter

P3 : PMK 50\% + ferrolit 50\% + 4 rumpun melati air + air lindi 10 liter 
Berdasarkan Tabel 6 dapat dilihat bahwa nilai $\mathrm{pH}$ air lindi memiliki nilai yang berbeda. Pada perlakuan $0 \mathrm{pH}$ pada hari 10 dan hari 30 masih mengalami penurunan selama 30 hari pengamatan. Pada hari ke 20, perlakuan 1 mengalami peningkatan $\mathrm{pH}$, namun pada perlakuan $2 \mathrm{pH}$ menurun. Dan dihari terakhir pengamatan (hari 30 ) $\mathrm{P} 1$ mengalami penurunan $\mathrm{pH}$ kembali sedangkan pada $\mathrm{P} 2 \mathrm{pH}$ meningkat.

g. Efektivitas Daun Melati Air (Echinodorus palaefolius) Dalam Mengakumulasi Logam Berat

Nilai efektivitas melati air dan media penyaring terhadap air lindi dapat dilihat pada Tabel 7:

Tabel 7 : Rekapitulasi Nilai Efektivitas Daun Melati Air Dalam Mengakumulasi Logam Berat $\mathrm{Fe}$ dan $\mathrm{Cr}$

\begin{tabular}{|c|c|c|c|r|r|r|}
\hline \multirow{2}{*}{ Parameter } & \multirow{2}{*}{ Unit } & Perlakuan & \multicolumn{4}{|c|}{ Efektivitas (EP) (\%) } \\
\cline { 3 - 7 } & & $\begin{array}{c}\text { Hari } \\
\text { ke 0 }\end{array}$ & $\begin{array}{c}\text { Hari ke } \\
10\end{array}$ & $\begin{array}{c}\text { Hari ke } \\
20\end{array}$ & $\begin{array}{c}\text { Hari ke } \\
30\end{array}$ \\
\hline \multirow{2}{*}{$\begin{array}{c}\text { Logam Berat } \\
\text { Fe Daun } \\
\text { Melati Air }\end{array}$} & $\mathrm{mg} / \mathrm{L}$ & $\mathrm{P} 2$ & 0 & 5,721 & 11,984 & 16,755 \\
\cline { 3 - 7 } & & $\mathrm{P} 3$ & 0 & 5,702 & 8,114 & 14,659 \\
\hline \multirow{2}{*}{$\begin{array}{c}\text { Logam Berat } \\
\text { Cr Daun } \\
\text { Melati Air }\end{array}$} & $\mathrm{mg} / \mathrm{L}$ & $\mathrm{P} 1$ & 0 & 3,153 & 7,157 & 10,242 \\
\cline { 3 - 7 } & & $\mathrm{P} 2$ & 0 & $-0,342$ & 5,944 & 7,956 \\
\cline { 3 - 7 } & & 0 & $-1,015$ & 2,503 & 6,187 \\
\hline
\end{tabular}

Berdasarkan Tabel 7 dapat dilihat bahwa efektivitas parameter konsentrasi logam berat $\mathrm{Fe}$ dan $\mathrm{Cr}$ yang terakumulasi pada daun melati air, nilai efektivitas Fe yang tertinggi yaitu pada perlakuan 1 hari ke 30 $(32,843 \%)$ dan nilai efektivitas $\mathrm{Cr}$ yang tertinggi yaitu juga pada perlakuan 1 hari ke $30(10,242 \%)$.

Berdasarkan hasil penelitian bahwa dari nilai efektivitas daun melati air (Echinodorus palaefolius) dalam mengakumulasi logam berat $\mathrm{Fe}$ dan $\mathrm{Cr}$ yang memiliki nilai tertinggi yaitu pada perlakuan P1 yang menggunakan media PMK (Podzolik Merah Kuning) dengan tumbuhan melati air pada hari ke 30. Hal ini disebabkan karena pada media PMK tidak efektif menyerap logam berat yang ada pada air lindi. Sehingga logam berat Fe dan $\mathrm{Cr}$ banyak terserap di daun melati air.

\section{KESIMPULAN}

Disimpulkan bahwa perlakuan yang efektif dalam mengakumulasi logam berat $\mathrm{Fe}$ dan $\mathrm{Cr}$ pada daun melati air (Echinodorus palaefolius) yaitu terdapat pada perlakuan 1 hari ke 30 menggunakan media penyaring PMK dengan tumbuhan melati air. Nilai efektivitas akumulasi logam berat $\mathrm{Fe}$ pada daun melati air sebesar $32,843 \%$ dan nilai efektivitas akumulasi logam berat $\mathrm{Cr}$ pada daun melati air sebesar 10,242\%. 


\section{DAFTAR PUSTAKA}

Ali, M. 2011. Monograf Rembesan Air Lindi (leachate) Dampak pada Tanaman Pangan dan Kesehatan. UPN Press : Surabaya.

Hanafiah, K, A. 2011. Rancangan Percobaan Teori \& Aplikasi. Ed. 3. Raja Grafindo Persada. Jakarta.

Murni, P. 2009. Peningkatan pH Tanah Podsolik Merah Kuning Melalui Pemberian Abu dan Hubungannya dengan Aktivitas Mikroorganisme Pengikat Nitrogen. Biospecies. Vol. 2. Nol. 2. Hal. 18-20.

Safrani. 2007. Kajian penfaatan Media Penyaringan dan Tumbuhan Air Setempat untuk Pengendalian Limbah Cair pada Sub-DAS Tapung Kiri, Propinsi Riau. Disertasi, Sekolah Pasca sarjana, Institute Pertanian Bogor. Bogor. Tidak di terbitkan.

Sari, E., \& Sari, M. 2014. Analisis Kualitas Air Lindi Tempat Pembuangan Akhir (TPA) Muara Fajar dan Pengaruhnya Terhadap Air Tanah. Laporan Penelitian. Fakultas Keguruan dan Ilmu Pendidikan Universtas Lancang Kuning Pekanbaru. Tidak di terbitkan.

Sari, D, Y. 2015. Efektivitas Media Penyaring dan Kayu Apu (Pistia $\begin{array}{llr}\text { stratiotes } & \text { l.) } & \text { dalam } \\ \text { Fitoremediasi } & \text { Air } & \text { Lindi }\end{array}$ (leachate). Skripsi. Fakultas Keguruan dan Ilmu Pendidikan Universtas Lancang Kuning Pekanbaru. Tidak diterbitkan.

Sosrosumihardjo, D. 2010. Mengenal Logam Beracun. Badan Pengawas Obat dan Makanan RI.

Sugiarto. 2013. Analisis Ulang Kelayakan Tempat Penampungan Sampah Dengan Perbaikan Metode Sanitary Landfill di TPA Muara Fajar Rumbai.

Tersedia:http://repository.uinsus ka.ac.id/3833/2/BAB\%20I\%20P ENDAHULUAN.pdf/.

Sugiyono. 2008. Metodologi Penelitian Pendidikan Pendekatan Kuantitatif, Kualitatif dan R\&D. Tersedia: http://eprints.walisongo.ac.id/.

Sundari, A. 2015. Efektivitas Media Penyaring dan Melati Air (Echinodorus palaefolius) Dalam Fitoremediasi Air lindi (Leachate). Skripsi. Fakultas Keguruan dan Ilmu Pendidikan Universtas Lancang Kuning Pekanbaru. Tidak diterbitkan.

Yatim, E.,M., \& Mukhlis. 2013. Pengaruh Lindi (leachate) Sampah Terhadap Air Sumur Penduduk Sekitar Tempat Pembuangan Akhir (TPA) Air Dingin. Jurnal Kesehatan Masyarakat. Vol. 7, No. 2. 